\title{
Partnerships and the paradoxes of parenting children living with illness
}

\author{
Duncan C Randall PhD, Principle Teaching Fellow, University of Southampton
}

It seems obvious to state that children need parents. but yet in stating the blindingly obvious we can sometimes uncover neglected ideas, hiding in plain sight. As Berry Mayal (2002) pointed out children need an adult who is available and reliable, it does not matter who that is but, some adult has to for fill this role to facilitate children's maturation into adult society. It seems equally obvious that illness would disrupt a child's relationships. Lastly it does not take a genius to observe that nurses work with children and this requires them to work with those who care for children (in the main the available and reliable adults in the child's life).

So why have nurses paid so little attention to the ways in which children living with illness are parented? Sure, there are papers on parental coping with specific diseases and conditions (Allen 2014, Cataudella and Zelcer 2012, Wei et al 2016) and work by in the main psychologists on parental coping (Heath, et al 2016, Darlington et al 2017), but very little from nurses (Coyne 2008). Consider the following nurses rely on parents to deliver care. Indeed, nurses might want to facilitate and encourage parental care as an experience of childhood, that is that children benefit from being looked after by their parents(carers) when they are unwell (Randall 2018). This experience might be shared with other children who have illness in childhood or other challenges and who are supported and nurtured by their parents(carers). Yet we have no measures to assess how well parents are parenting a child who lives with illness. We do not have a valid and reliable way to determine if parents are able to undertake their role as parents, nor if they have the capacity, skills and understanding to deliver nursing care delegated by nurses and the medical team.

Often nurses will use an intuitive approach. Stating that families are not coping or mothers/fathers are close to breaking down! While intuition can be helpful it can also be subject to unconscious bias. Some carers may show their distress when feeling under pressure, others may seek to hide their distress, or display behaviours that nurses do not associate with being unable to cope. Thus while intuition may identify some parents who are struggling, it may not help nurses to identify all parents. If an intuitive unstructured approach is adopted there is also a danger that those who shout loudest and in behave in acceptable ways are recognised and supported while those who are not so articulate or who appear challenging, aggressive or disengaged are dealt with very differently.

Without valid and reliable ways of assessing parental capacity and coping we risk focusing time and resources on carers who could, with a little support, care for their child, while those who need extra support and resources are left to fend for themselves. To sink or swim as a parents.

The dynamic relationship between children, carers and nurses also affects resourcing and delivery of nursing care. As stated above and elsewhere (Randall 2018) it may be desirable for parents to care for their child. Indeed, it has been noted that parents often assume nursing roles and that nurses rely on parents undertaking nursing roles to deliver care (Coyne 2008). Yet the limited literature on children's nursing workforce planning does not mention the effect of parental participation in estimations of staffing numbers (Bagnasco et al 2018, 2019, North et al 2019,Tucker et al 2009). Almost exclusively the work on staffing levels has been undertaken in adult nursing settings, where the carers role is very different. With a better understanding of the needs of parents' capacities and 
coping styles nurses could more reliably delegate nursing care. Without such measures we risk burdening parents to care for their child when they are unable to do so safely. We may over burden carers causing distress and eventually for them to reject the caring role. We may also facilitate understaffing with an expectation that all parents are equally able, at all times, to deliver delegated care, which leads to workforce planning where fewer nurses are employed assuming that care will be delivered by parents/carers.

In considering the child who lives with illness and the effects on the practices and customs of parenting it can be helpful to consider a very broad definition. Obvious is the child themselves who have a disease or condition, but children also live with parents/carers who are ill (Finch and Gibson, 2009, Golsäter et al 2016) and with siblings and peers. Any assessment of parenting then needs to include the effect of illness on parents capacity to parent and competing demands of other children for whom the carer may have responsibility. As well as the effect illness in parents and or siblings/peers has on the child themselves. Children who live with illness is then a complex interaction between disease processes and social roles which affect psychosocial and physical function.

In addition, who accepts and who is permitted to reject responsibility for a child's care is often highly dependent on cultural/social and political context. In different cultures and society there are different expectations of parents, of children and of nurses. We might expect then that different approaches to supporting parents and different levels of parental participation will emerge in different communities.

Where does this leave us! It's complicated for sure however, perhaps why nurses have not ventured into this arena before or done so only partially is because layer on top of the complexity are highly charged emotions. Guilt is said to be an integral part of parenting and social and cultural judgements abound in relation to parenting. Which is to be expected as nurturing the next generation is a vital social and cultural, as well as economic function in communities.

The challenge is then to recognise the need to support carers in parenting the child living with illness and the role carers have in children's nursing care design, delivery and evaluation. To make this work public, visible, to children their carers and nurses. Which must include understanding how working in partnership affects the workforce planning and development for nurses who look after children.

References

Allen K.A (2014) Parental decision-making for medically complex infants and children: An integrated literature review. International Journal of Nursing Studies.51(9) 1289-1304

https://doi.org/10.1016/j.ijnurstu.2014.02.003

Bagnasco A, Zanini M, Aleo G, Catania G, Kalisch B. J, and Sasso L (2018) Development and validation of the MISSCARE survey -Pediatric version. Journal of Advanced Nursing, 74, 2922-2934. https://doi.org/10.1111/jan.13837

Bagnasco A, Dasso N, Rossi S, Timmins F, Aleo G, Catania G Zanini M and Sasso L (2019) Missed care in children's nursing-An emergent concern. Journal of Advanced Nursing https://doi.org/10.1111/jan.13965

Cataudella D.A and Zelcer S (2012) Psychological Experiences of Children with Brain Tumors at End of Life: Parental Perspectives. Journal of Palliative Medicine. 15 (11) DOI: 10.1089/jpm.2011.0479 
Coyne I (2008) Disruption of parent participation: nurses' strategies to manage parents on children's wards. Journal of Clinical Nursing. 17(23), 3150-3158 https://doi.org/10.1111/j.1365-

2702.2006.01928.x

Darlington AS.E, Korones D.N and Norton S.A (2017) Parental coping in the context of having a child who is facing death: A theoretical framework. Palliative and Supportive Care 16(4) 432-441

https://doi.org/10.1017/S1478951517000463

Finch A and Gibson F (2009) How do young people find out about their parent's cancer diagnosis: a phenomenological study. European Journal of Oncology Nursing. 13 (3), $213 e 222$.

Golsäter M, Henricson M, Enskär K and Knutsson S (2016) Are children as relatives our responsibility? -How nurses perceive their role in caring for children as relatives of seriously ill patients. European Journal of Oncology Nursing 25, 33-39

https://doi.org/10.1016/i.ejon.2016.09.005

Heath, G, Farre, A \& Shaw, K (2016) Parenting a child with chronic illness as they transition into adulthood: A systematic review and thematic synthesis of parents' experiences'. Patient Education and Counselling. https://doi.org/10.1016/j.pec.2016.08.011

Mayall B (2002) Towards a sociology for childhood: Thinking from children's lives. Birmingham: Open University Press.

North N, Shung-King M and Coetzee M (2019) The children's nursing workforce in Kenya, Malawi, Uganda, South Africa and Zambia: generating an initial indication of the extent of the workforce and training activity. Human Resources for Health 17 article 30 https://human-resourceshealth.biomedcentral.com/articles/10.1186/s12960-019-0366-4

Randall D (2018) Pragmatics and Parenting. Journal of Pediatric Nursing, 43 e35-e38 https://doi.org/ 10.1016/j.pedn.2018.08.009

Tucker J.S, Parry G, Draper E, McKee L and Skatun D (2009) The impact of changing workforce patterns in UK paediatric intensive care services on staff practice and patient outcomes; Report for the National Institute for Health Research Service Delivery and Organisation program. Available from http://www.netscc.ac.uk/hsdr/files/project/SDO FR 08-1519-96 V01.pdf

Wei H, Roscigno C.I, Swanson K.M, Black B.P, Hudson-Barr D and Hanson C.C (2016) Parents' experiences of having a child undergoing congenital heart surgery: An emotional rollercoaster from shocking to blessing. Heart \& Lung. 45(2) 154-160 https://doi.org/10.1016/j.hrtlng.2015.12.007 